\title{
Análise microbiológica e caracterização eletroforética do queijo mussarela elaborado a partir de leite de búfala
}

\author{
Microbiological analysis and electrophoretic characterization of mozzarella cheese made from buffalo milk
}

\author{
Kate Aparecida BUZI ${ }^{1 \star}$, José Paes de Almeida Nogueira PINTO', \\ Paulo Roberto Rodrigues RAMOS ${ }^{2}$, Germano Francisco BIONDI ${ }^{1}$
}

\begin{abstract}
Resumo
O presente trabalho visou avaliar a qualidade microbiológica de queijos mussarela elaborados a partir de leite de búfala, adquiridos do comércio varejista, assim como, verificar a sua autenticidade, averiguando a possível presença de leite de vaca no produto. As análises microbiológicas compreenderam contagem de coliformes totais e E. coli, contagem de Staphylococcus coagulase-positiva e pesquisa de Salmonella spp.; enquanto que, para a determinação da pureza das mussarelas, a técnica utilizada foi a eletroforese em gel de poliacrilamida. Com base nos resultados obtidos na avaliação microbiológica, pode-se afirmar que $98 \%$ das amostras estão dentro dos padrões microbiológicos legais vigentes, embora algumas delas tenham apresentado valores elevados para coliformes totais, os quais indicam inadequadas condições de higiene durante a fabricação dos queijos. Entretanto, $2 \%$ das amostras encontram-se em desacordo com a legislação, uma vez que apresentaram populações de coliformes fecais acima do permitido, como resultado de uma alta contaminação por E. coli. Mediante a caracterização eletroforética, detectou-se a presença de leite de vaca em $22 \%$ das amostras, adicionado, provavelmente, de forma intencional.

Palavras-chave: mussarela; búfalo; microbiologia; eletroforese; adulterações.
\end{abstract}

\begin{abstract}
This study evaluated the microbiological quality of mozzarella cheese made from buffalo milk obtained from retail outlets and validated their authenticity by checking the product for the possible presence of cow milk. The microbiological analysis included counts of $E$. coli, total coliform, positive coagulase Staphylococcus, and Salmonella spp. For the determination of mozzarella purity, we used polyacrylamide gel electrophoresis. Based on the results of the microbiological evaluation, we can state that $98 \%$ of samples comply with the legal microbiological standards although some have shown high values of total coliforms, which indicates poor hygienic conditions during manufacturing. However, $2 \%$ of the samples showed fecal coliform populations exceed the legal limit due to high E. coli contamination. Electrophoresis detected cow milk in $22 \%$ of the samples, which was probably added intentionally.

Keywords: mozzarella; buffalo; microbiology; electrophoresis; adulterations.
\end{abstract}

\section{Introdução}

Os búfalos são tradicionalmente considerados como animais de tração e produtores de carne, porém, com a escolha de animais selecionados e a obtenção de melhores níveis de desempenho dos rebanhos, os produtores têm demonstrado um crescente interesse pela produção leiteira, com vistas sobretudo ao fornecimento de leite para a elaboração de derivados (CUNHA NETO; OLIVEIRA, 2003).

A maior vantagem do leite bubalino, em relação ao leite de outras espécies, é o teor elevado de proteínas e gorduras, sendo o seu aproveitamento industrial efetivamente extraordinário, chegando, comparativamente, a sobrepujar o rendimento do leite bovino em mais de $40 \%$ (HÜNH; LOURENÇO JUNIOR; MOURA CARVALHO, 1980; HÜNH; FERREIRO; MOURA CARVALHO, 1982; NADER FILHO, 1984).
A partir do leite de búfala, podem-se elaborar diversos tipos de queijos, requeijão, manteiga, iogurte, etc., entretanto a mussarela é, sem dúvida, o produto principal, sendo a maior parte deste leite destinada à sua fabricação.

A carga microbiana do leite cru é de extrema importância na qualidade final dos produtos lácteos, sendo que é praticamente impossível melhorar as propriedades de um derivado, se o número de microrganismos inicialmente presentes no leite in natura é elevado (HÜNH et al., 1980; HÜNH; FERREIRO; MOURA CARVALHO, 1982).

Para que o processo de fabricação atinja o seu ideal, a contagem total de bactérias do leite destinado à fabricação de mussarela, deve estar entre 5,0 X $10^{3}$ a 5,0 X $10^{5} \mathrm{UFC} . \mathrm{mL}^{-1}$. Se

Recebido para publicação em 22/2/2007

Aceito para publicação em 6/1/2009 (002316)

Departamento de Higiene Veterinária e Saúde Pública, Faculdade de Medicina Veterinária e Zootecnia, Universidade Estadual Paulista - UNESP, CP 572, CEP 18618-000,

Botucatu - SP, Brasil, E-mail: katebuzi@yahoo.com.br

${ }^{2}$ Departamento de Física e Biofísica, Instituto de Biociências, Universidade Estadual Paulista - UNESP, CP 510, CEP 18618-000, Botucatu - SP, Brasil

${ }^{*}$ A quem a correspondência deve ser enviada 
este apresentar alta contagem microbiana, além de modificar as características organolépticas, como sabor, odor e maciez, poderá também alterar a coagulação da massa e consequentemente a textura do queijo, refletindo diretamente no rendimento da produção (AMANTE et al., 2001).

Apesar da importância da pasteurização, na Itália, ainda hoje, a mussarela é elaborada a partir do leite cru de búfala com o propósito de não alterar o processo tecnológico, além de garantir as características organolépticas particulares e inerentes ao produto. Pelo fato do nosso sistema de produção seguir o italiano, muitos laticínios brasileiros também trabalham com leite cru.

Para Del Prato (1998), a teoria de que o processo de filagem em água quente equivale à pasteurização é errônea, pois, durante o processo de filagem, as bactérias podem estar protegidas pelas caseínas e pelos glóbulos de gordura, que possuem uma notável capacidade de isolamento térmico.

As flutuações sazonais na disponibilidade do leite de búfala e o preço mais elevado comparado com o leite de vaca são um incentivo para que os laticínios o adicionem durante a elaboração da mussarela de búfala. Por isso, atualmente, são aplicados diversos métodos laboratoriais a fim de se detectar tal adulteração.

Similarmente como ocorreu na Itália, no Brasil, foi criado um selo de pureza. Elaborado pela Associação Brasileira de Criadores de Búfalos (ABCB), este é concedido ao laticínio que, mediante teste de eletroforese, utiliza exclusivamente o leite bubalino em seus produtos (GLASS, 2006).

O presente trabalho teve como objetivos avaliar a qualidade microbiológica das mussarelas de búfala distribuídas no comércio varejista, no sentido de verificar a sua inocuidade e averiguar a autenticidade de tais queijos, investigando, através da caracterização eletroforética, a possível adição de leite de vaca ao produto.

\section{Material e métodos}

No período de julho a novembro de 2005, foram feitas colheitas de queijos mussarela elaborados exclusivamente com

Quadro 1. Listagem de amostras de mussarela de búfala, por procedência.

\begin{tabular}{|lc|}
\hline \multicolumn{1}{|c|}{ Amostras } & Municípios \\
$10-11-14-42-49-50$ & Alambari \\
$17-18$ & Araçoiaba da Serra \\
16 & Araras \\
$5-6-7-19-35-36-39-47$ & Bocaina \\
$4-13-27-28-29-30-$ & Dourado \\
$34-38-41-43-44-45-46$ & \\
$8-9-23-48$ & Pompéia \\
12 & Registro \\
$3-21-22$ & São Carlos \\
2 & São Miguel Arcanjo \\
$31-32-33$ & Santa Rita de Passa Quatro \\
$24-25-26$ & Sete Barras \\
\hline
\end{tabular}

leite de búfala e comercializados em estabelecimentos varejistas de diferentes cidades do Estado de São Paulo. As 50 amostras (Quadro 1), em suas embalagens originais, foram acondicionadas em caixas isotérmicas com gelo reciclável, encaminhadas ao Laboratório de Análises Microbiológicas - Inspeção Sanitária de Alimentos de Origem Animal, da Faculdade de Medicina Veterinária e Zootecnia e ao Laboratório de Fracionamento de Proteínas - Departamento de Física e Biofísica, do Instituto de Biociências, ambos pertencentes à UNESP/ Botucatu, para que pudessem ser processadas e analisadas.

\subsection{Análises microbiológicas}

As metodologias aplicadas para as análises microbiológicas foram realizadas segundo o disposto na Instrução Normativa SDA n ${ }^{\circ} 62$, de 26 de agosto de 2003, do Ministério da Agricultura, Pecuária e Abastecimento (BRASIL, 2004), combinada com a metodologia preconizada por Andrews et al. (1998). Para a contagem de coliformes totais e E. coli, utilizou-se o Sistema de Placas Petrifilm (3M), seguindo as recomendações do fabricante. Foram preparadas diluições em série $\left(10^{-1}\right.$ a $\left.10^{-5}\right)$ para as contagens de coliformes totais e Escherichia coli e de Staphylococus coagulase-positiva, enquanto que, para a determinação de Salmonella spp., a amostra foi transferida diretamente para o meio de cultivo de pré-enriquecimento.

\subsection{Eletroforese em gel de poliacrilamida}

Utilizou-se a técnica de eletroforese em gel de poliacrilamida vertical, alcalina ( $\mathrm{pH} 8,3$ ), em sistema de tampões descontínuos, descrita por Hames e Rickwood (1990) com algumas modificações descritas por Ramos (1992). Para a identificação das frações das caseínas, foram preparados géis de separação a $10 \%$ e de empilhamento a $4 \%$, conforme descrito nas Tabelas 1 e 2 , respectivamente.

No gel, após a sua polimerização, aplicaram-se aproximadamente $10 \mu \mathrm{L}$ de cada amostra e dos controles de vaca e de búfala, os quais foram obtidos no Laboratório de Fracionamento de Proteínas, a partir de mussarelas sabidamente elaboradas com leite de vacas e búfalas, respectivamente.

Fixado em uma cuba vertical, o gel foi ligado a uma fonte elétrica (Pharmacia - Eletrophoresis Power Supply - EPS 600), sendo a eletroforese realizada em uma corrente constante de

Tabela 1. Componentes do gel de separação a 10\% de poliacrilamida para PAGE.

\begin{tabular}{lc}
\multicolumn{1}{c}{ Componentes } & Quantidade \\
\hline $\begin{array}{l}\text { Solução A (30\% de Acrilamida e } \\
\text { 0,8 de Bis-acrilamida) }\end{array}$ & $10 \mathrm{~mL}$ \\
Solução B (Tris 36,3 g, $\mathrm{HCl}(1 \mathrm{M})$ & $3 \mathrm{~mL}$ \\
$48 \mathrm{~mL}$, q.sp.100 mL, pH 8,8) & \\
Persulfato de amônio $10 \%$ & $200 \mu \mathrm{L}$ \\
TEMED & $11 \mu \mathrm{L}$ \\
Uréia 6M & $16,8 \mathrm{~mL}$ \\
\hline
\end{tabular}


$200 \mathrm{~V}$ e amperagem de $10 \mathrm{~mA}$, sob temperatura de refrigeração $\left(4^{\circ} \mathrm{C}\right)$, durante aproximadamente 5 horas.

Terminada a corrida eletroforética, o gel foi corado e descorado. Suas imagens foram salvas e digitalizadas através do VDS (Pharmacia Biotech) e através de um software analisador de imagens (Image Master - Pharmacia Biotech), do Departamento de Física e Biofísica, Instituto de Biociências, UNESP - Botucatu/ SP, determinou-se a mobilidade eletroforética relativa (RF) de cada banda proteica.

\section{Resultados e discussão}

Os valores obtidos nas contagens de coliformes totais e Escherichia coli. das amostras de mussarela de búfala se encontram na Tabela 3.

No que se refere aos coliformes totais, grande parte dos queijos analisados (74\%) apresentou contagens menores que $10^{1}$ UFC.g ${ }^{-1}$. Entretanto, foram obtidos resultados elevados, indicando, provavelmente, as inadequadas condições de higiene durante o processo de elaboração. Deve-se ressaltar que os valores encontrados na faixa de contagem entre $10^{5}$ e $10^{6} \mathrm{UFC}^{-1} \mathrm{~g}^{-1}$ correspondem às amostras contidas em embalagens com soro, o qual pode ter favorecido o crescimento dos microrganismos em função da sua atividade de água $\left(\mathrm{A}_{\mathrm{w}}\right)$, considerada como um fator importante na multiplicação bacteriana.

Ao analisarem mussarelas elaboradas com leite cru de búfala, Silva et al. (2004) verificaram que apesar do processo de filagem ter sido eficiente, permitindo a sobrevivência de apenas 0,04\% dos coliformes totais, a população média na massa pósfilagem ainda foi considerada alta $\left(3,49 \times 10^{3} \mathrm{NMP}^{-1}\right)$.

Apesar da legislação brasileira (Resolução RDC no 12 de 02/01/01) (ANVISA, 2005) não estabelecer limites de tolerância para os coliformes totais, torna-se necessária a sua contagem por serem indicadores das condições de higiene, pois, uma vez presentes no leite cru, geralmente são destruídos pelo processo de pasteurização. Altas contagens podem significar contaminação pós-processamento, limpeza e sanitização deficientes ou tratamentos térmicos ineficientes (GLASS, 2006).

Com relação aos coliformes fecais, o limite estabelecido pela Resolução RDC no 12 de 02/01/01 para mussarela é de $5 \times 10^{3}$ UFC. $^{-1}$. Considerado indicativo das condições higiênicosanitárias, este grupo está relacionado com contaminação fecal de animais de sangue quente, inclusive o homem, podendo originar-

Tabela 2. Componentes do gel de empilhamento a $4 \%$ de poliacrilamida para PAGE.

\begin{tabular}{lc}
\hline \multicolumn{1}{c}{ Componentes } & Quantidade \\
\hline Solução A (30\% de Acrilamida e 0,8 de & $2,6 \mathrm{~mL}$ \\
Bis-acrilamida) & $5 \mathrm{~mL}$ \\
Solução B (Tris 6 g, HCl(1M) $48 \mathrm{~mL}$, & \\
q.sp.100 mL, pH 6,8) & $2,5 \mu \mathrm{L}$ \\
Riboflavina 0,004\% & $9,9 \mathrm{~mL}$ \\
\hline
\end{tabular}

se também da deficiente sanitização das superfícies de trabalho na planta de processamento (NICOLAU et al., 2004).

A ocorrência de Escherichia coli, principal representante deste grupo, é a mais indicada para comprovar a contaminação fecal, já que tem como habitat exclusivo o trato intestinal do homem e de animais. A importância da sua presença no alimento está na patogenicidade de algumas cepas e na possibilidade de haver outros microrganismos patogênicos, representando assim, um risco em potencial para a saúde dos consumidores.

Quanto aos valores da Tabela 1 referentes à contagem de E. coli, observa-se que, apesar da maior parte das amostras ter apresentado populações menores que $10^{1} \mathrm{UFC} . \mathrm{g}^{-1}, 4 \%$ apresentaram valores entre $10^{3}$ e $10^{5} \mathrm{UFC}^{\mathrm{g}} \mathrm{g}^{-1}$. Entretanto, pode-se afirmar que apenas $2 \%$ delas encontram-se em desacordo com a legislação, uma vez que a contagem desse microrganismo ultrapassou os valores permitidos para coliformes fecais. Cortesi et al. (1997), ao analisarem mussarelas elaboradas com leite cru de búfala, armazenadas sob refrigeração $\left(6^{\circ} \mathrm{C}\right)$ por 7 dias em salmoura, não encontraram o microrganismo.

Olivieri (NADER FILHO, 1984), ao comparar duas marcas diferentes de mussarela de búfala, preparadas com leite pasteurizado, observou que todas as amostras apresentaram valores para coliformes fecais abaixo do estabelecido pela legislação, sendo que, resultados acima de $10^{2} \mathrm{UFC} . \mathrm{g}^{-1}$ foram encontrados em $27,8 \%$ das amostras da marca A (com soro) e em $8,3 \%$ das amostras da marca B (sem soro).

Todos os resultados referentes à contagem de Staphylococcus coagulase-positiva estiveram abaixo de $10^{2} \mathrm{UFC}^{-1}{ }^{-1}$, enquadrando-se, portanto, no padrão microbiológico para mussarela estabelecido pela Resolução RDC no 12 02/01/01, que tolera uma contagem de até $10^{3} \mathrm{UFC} . \mathrm{g}^{-1}$. Valores semelhantes foram obtidos por Olivieri (NADER FILHO, 1984), que apresentou somente contagens menores que $10^{2} \mathrm{UFC}^{-1} \mathrm{~g}^{-1}$ para o mesmo microrganismo neste tipo de queijo.

Embora os resultados obtidos por Silva et al. (NICOLAU et al., 2004) tenham mostrado o potencial microbiocida da filagem empregada na elaboração da mussarela de búfala, o Staphylococcus coagulase-positiva não foi totalmente eliminado, estando pre-

Tabela 3. Distribuição de 50 amostras de mussarela de búfala analisadas de acordo com os valores referentes às contagens de coliformes totais e E. coli.

\begin{tabular}{ccccc}
\hline $\begin{array}{c}\text { Faixa de } \\
\text { contagem em } \\
\text { UFC.g }{ }^{-1 *} \text { amostra }\end{array}$ & Coliformes totais & \multicolumn{2}{c}{ E. coli. } \\
\hline 0-I $10^{1}$ & 37 & 74 & 48 & 96 \\
$10^{1}-\mathrm{I} 10^{2}$ & - & - & - & - \\
$10^{2}-\mathrm{I} 10^{3}$ & 5 & 10 & - & - \\
$10^{3}-\mathrm{I} 10^{4}$ & 4 & 8 & 1 & 2 \\
$10^{4}-\mathrm{I} 10^{5}$ & 2 & 4 & 1 & 2 \\
$10^{5}-\mathrm{I} 10^{6}$ & 2 & 4 & - & - \\
Total & 50 & 100 & 50 & 100 \\
\hline
\end{tabular}

${ }^{\star} \mathrm{UFC}_{\mathrm{g}}{ }^{-1}=$ Unidade formadora de colônia/g. 
sente em $11 \%$ das amostras. Entretanto, antes do processo, $50 \%$ destas eram negativas, indicando uma provável contaminação pelo manipulador.

O trabalho apresentado por Nicolau et al. (HÜNH et al., 1982) objetivou investigar a origem (humana ou bovina) das linhagens de $S$. aureus isoladas de amostras de mussarela, colhidas em diferentes etapas do processamento. Eram de origem humana $62,1 \%$ das linhagens, evidenciando-se a participação dos manipuladores na contaminação, desde a origem da matéria-prima até a obtenção do produto final.

De acordo com os resultados da pesquisa de Salmonella spp., todas as amostras analisadas foram negativas, estando em conformidade com a Resolução RDC no 12 02/01/01, a qual determina a ausência deste microrganismo em $25 \mathrm{~g}$ do produto analisado. Coincidentemente, nos trabalhos relatados por Olivieri (NADER FILHO, 1984) e Silva et al. (NICOLAU et al., 2004), todas as amostras analisadas do queijo em questão mostraram-se negativas para Salmonella spp.

Com base nos resultados obtidos, pode-se afirmar que as amostras analisadas apresentaram, em geral, uma boa qualidade microbiológica, em relação aos microrganismos estudados. A contaminação, quando observada, provavelmente teve origem nas etapas pós-pasteurização, já que todas as amostras eram provenientes de estabelecimentos sob inspeção oficial (federal ou estadual), que exige que a elaboração de qualquer derivado lácteo seja realizada a partir de leite pasteurizado.

Assim, considera-se que a não observância de alguns padrões microbiológicos em algumas amostras tenha sido oriunda de condições inadequadas de higiene durante a elaboração de tais queijos, que permitiram a recontaminação do produto após a etapa de pasteurização do leite. Esta recontaminação, provavelmente, foi atenuada pelo efeito microbiocida da filagem, que apesar de não ser suficiente para garantir um padrão de qualidade microbiológica, auxiliou na redução dos microrganismos, como já verificado por outros autores (SILVA; PANETTA; ISHIZUKA, 1999).

Quanto à pureza das mussarelas de búfala, através da eletroforese em gel de poliacrilamida, observou-se a diferença de mobilidade das frações homólogas das caseínas de origem bovina e bubalina. Baseado nos resultados referentes às mobilidades relativas (RF) de cada banda, comprovou-se a presença do leite de vaca em $22 \%$ das amostras analisadas. Com exceção de apenas uma, todas essas amostras indicavam no rótulo, o leite de búfala como única matéria-prima utilizada.

Verificou-se ainda que aquelas amostras que apresentavam o selo de pureza impresso na embalagem continham apenas leite bubalino na sua composição, comprovando assim a sua veracidade.

De acordo com as Normas Técnicas Especiais Relativas a Alimentos e Bebidas (SÃO PAULO, 1990), a mussarela é o queijo de massa filada, não prensada, obtido a partir de leite de vaca, de cabra, de ovelha, de búfala, ou com qualquer combinação de dois ou mais destes leites. Por não existir nenhuma legislação referente ao uso exclusivo de leite de búfala para a fabricação dessa mussarela, é permitida a adição do leite de vaca ao produto.
Entretanto, tal informação deve estar contida no rótulo, caso contrário, constitui-se numa fraude.

\section{Conclusões}

A maior parte (98\%) das amostras de mussarela de búfala analisadas está em conformidade com os padrões microbiológicos legais vigentes.

Uma parcela destas amostras apresentou resultados elevados para coliformes totais, indicando, provavelmente, inadequadas condições de higiene durante o seu processo de fabricação.

As amostras que se encontram em desacordo com a legislação vigente por terem apresentado populações elevadas de coliformes fecais, tiveram ainda altas contagens de E. coli, evidenciando a contaminação fecal do alimento, tornando-o um risco em potencial, pela possibilidade de conter outros agentes patogênicos.

Medidas mais efetivas de higiene devem ser implantadas desde a obtenção do leite até as diferentes fases de elaboração dos queijos, como forma de poder oferecer aos consumidores, produtos com melhor qualidade e segurança.

Uma considerável porcentagem (22\%) das amostras de mussarela mostrou em sua composição a presença do leite de vaca, sugerindo uma adição de forma intencional. Tal fato pode ter ocorrido durante a fase de elaboração do produto ou durante o fornecimento do leite.

\section{Agradecimentos}

À Coordenação de Aperfeiçoamento de Pessoal de Nível Superior (CAPES) pela bolsa de mestrado concedida ao primeiro autor.

\section{Referências bibliográficas}

AGÊNCIA NACIONAL DE VIGILÂNCIA SANITÁRIA - ANVISA. Resolução - RDC no 12, de 02 de janeiro de 2001. Disponível em: <http: //www.anvisa.gov.br> . Acesso em: 05 Abr. 2005.

AMANTE, L. et al. Valutazione dei puti critici della mungitura in aziende di bufale di pianura e di colina del basso Lazio. In: CONGRESSO NAZIONALE SULL'ALLEVAMENTO DEL BÚFALE, 1, 2001, Salermo. Annali... Salermo, 2001. p. 251-255.

ANDREWS, W. H. et al. Salmonella. In: Food and Drug Administration - Bacteriological Analytical Manual: Revision A. Gaithersburg: AOAC INTERNATIONAL, 1998. p. 5.01- 5.20

BRASIL. Ministério da Agricultura, Pecuária e Abastecimento. Instrução Normativa SDA 62, de 26 de agosto de 2003. Métodos microbiológicos para análise de alimentos de origem animal e água. Brasília, 2003. 265p. Disponível em: < http://www.agricultura. gov.br>. Acesso em: 21 Abr. 2004.

CORTESI, M. L. et al. Behaviour of Salmonella senftenberg during manufacture of buffalo mozzarella cheese: preliminary researchs. In: WORLD BUFFALO CONGRESS, 5, 1997, Caserta. Proceedings... Caserta, 1997. p. 266-271.

CUNHA NETO, O. C.; OLIVEIRA, C. A. F. Aspectos da qualidade microbiológica do leite de búfala. Higiene Alimentar, v. 17, n. 110, p. 18-23, 2003. 
DEL PRATO, O. S. Tratado di tecnología casearia. Bologna: [s.n.], 1998. 1070p.

GLASS, V. Pureza garantida. Revista Globo Rural. Disponível em: $<$ http://globorural.globo.com/barra.asp.d=/edic/191/rep.bufalaa. htm>. Acesso em: 15 Mar. 2006.

GUERREIRO, M. G. Bacteriologia especial: com interesse à saúde pública. Porto Alegre: Sulina, 1984.

HAMES, B. D.; RICKWOOD, D. Electrophoresis of proteins. 2 ed. New York: [s.n], 1990. 383 p.

HÜNH, S.; LOURENÇO JUNIOR, J. B.; MOURA CARVALHO, L. O. Características do leite de búfalas da raça Mediterrâneo e mestiço Murrah-Mediterrâneo. Belém: EMBRAPA-CPATU, 1980.

HÜNH, S.; FERREIRO, L.; MOURA CARVALHO, L. O. Estudo comparativo da composição química do leite de zebuínos e bubalinos. Belém: EMBRAPA-CPATU, 1982.

NADER FILHO, A. Estudo da variação do ponto crioscópico do leite de búfala. Revista do Instituto de Laticínios Cândido Tostes, v. 39, n. 234, 1984.

NICOLAU, E. S. et al. Staphylococcus aureus no processamento de queijo mussarela: detecção e avaliação da provável origem das linhagens isoladas. Higiene Alimentar, v. 18 , n. 125 , p. 51-56, 2004.

OLIVIERI, D. A. Avaliação da qualidade microbiológica de amostras de mercado de queijo mussarela, elaborado a partir de leite de búfala (Bubalus bubalis). Piracicaba, 2004. 61p. Dissertação (Mestrado) - Escola Superior de Agricultura "Luiz de Queiroz", Universidade de São Paulo, Piracicaba.

RAMOS, P R. R. Polimorfismo bioquímico de proteínas séricas do leite de vaca da raça holandês, puras por cruzamento, variedade malhada de preto. Botucatu, 1992. 131p. Tese (Doutorado em Ciências Biológicas) - Instituto de Biociências, UNESP.

SÃO PAULO (Estado). Código sanitário: decreto $\mathrm{n}^{\circ} 12.342$, de 27 de setembro de 1978: regulamento da promoção, preservação e recuperação da saúde no campo de competência da Secretaria de Estado da Saúde (revisto e atualizado até dezembro de 1990). 5 ed. São Paulo: Imprensa Oficial do Estado, 1992. p.145-343.

SILVA, E. O. T. R.; PANETTA, J. C.; ISHIZUKA, M. M. Efeito microbiocida da fase da filagem, durante a fabricação de mozzarella elaborada com leite cru de búfala. Higiene Alimentar, v. 13, n. 59, p. 28-34, 1999. 